\title{
Metafora Baru dalam Seni Lukis Kontemporer Berbasis Ikonografi Relief Yeh Pulu
}

\author{
I Wayan Adnyana ${ }^{1}$, Anak Agung Gede Rai Remawa ${ }^{2}$, Ni Luh Desi In Diana Sari ${ }^{3}$ \\ ${ }^{1}$ Seni Murni, Fakultas Seni Rupa dan Desain ISI Denpasar \\ ${ }^{2}$ Desain Interior, Fakultas Seni Rupa dan Desain ISI Denpasar \\ ${ }^{3}$ Desain Komunikasi Visual, Fakultas Seni Rupa dan Desain ISI Denpasar
}

kun_adnyana@yahoo.com

Artikel ini merupakan luaran penelitian terapan tahun ketiga, bertujuan untuk mengungkap penciptaan seni lukis kontemporer berbasis ikonografi relief Yeh Pulu. Penciptaan seni lukis dilakukan melalui dua tahap: analisis ikonografi untuk menemukan konsep, dan tahap penciptaan karya. Tahap analisis menggunakan teori ikonologi Panofsky melalui tiga tingkatan analisis: pra-ikonografi, analisis ikonografi, dan analisis ikonologi. Artikel ini mengedepankan pada analisis (interpretasi) ikonologis untuk menginvestigasi makna dari motif, simbol, dan alegori atas konteks budaya yang melekat pada objek analisis (D'Alleva, 2005). Interpretasi ini menemukan konsep metafora baru, yakni kepahlawanan orang-orang biasa. Pada praktik penciptaan seni lukis kontemporer, metafora dibentuk dengan tiga pendekatan estetik, yakni pembingkaian ulang, perombakan ulang, dan pemindahan ke ruang atau lokus global kontemporer. Artinya, figur ikonik relief Yeh Pulu dibingkai ulang dalam ruang lanskap baru, memindahkan yang kuno ke dalam konteks tata kehidupan masa kini, termasuk mobilitas pada ruang-ruang global.

Kata kunci: relief Yeh Pulu, ikonologi, metafora baru, tiga pendekatan estetik

\section{A New Metaphor in Contemporary Paintings Based On Iconographical Yeh Pulu Reliefs}

This article is an out put of practice-based research in third years, that aims explored contemporary paintings creation based on iconographic of Yeh Pulu reliefs. Paintings creation follows two steps: an iconographical analysis has discovered a concept, and created a contemporary painting based on studio experimentation. In analysis process used Panofsky's iconology theory follows three levels: pre-iconographic, iconographic analysis, and iconological analysis. This article wishes iconological interpretation (analysis) that investigates the meaning of motifs, symbols, and allegories in their culture contexts (D'Alleva, 2005). Interpretation has discovered a concept of a new metaphor, that heroism of common people. In contemporary painting creation process, a new metaphor created by three aesthetical approaches: reframing, recasting, and globalizing. Means, the iconic figures of Yeh Pulu reliefs reframed into new landscape, moved the ancient into recent time, as well as mobilized into global spaces.

Keywords: Yeh Pulu reliefs, iconology, new metaphor, and three aesthetical approaches

Proses Review : 1 - 18 April 2019, Dinyatakan Lolos: 22 April 2019 


\section{PENDAHULUAN}

Relief Yeh Pulu berlokasi di Desa Bedulu, Gianyar memiliki keunikan motif, simbol, maupun narasi. Pada penelitian penulis yang telah dilakukan dalam dua tahun terakhir, ditemukan konsep multinarasi (Adnyana, Remawa, dan In Diana Sari, 2018: 249). Konsep multinarasi dirumuskan dari analisis ikonografi, yang menerangkan bahwa antar adegan pada relief Yeh Pulu tidak selalu bersambung untuk saling menerangkan. Banyak adegan hadir justru untuk menerangkan dirinya sendiri.

Seperti, adegan penjual tuak, pengusung pacul, penunggang kuda, perburuan macan, dan lain-lain tidak bersambung dalam hubungan sebab-akibat. Adegan-adegan tersebut boleh disebut menerangkan keberagaman aktivitas sehari-hari manusia Bali pada jamannya. Keseluruhan adegan dengan keunikan pahatan tersebut menunjuk pada tema sentral yakni kepahlawanan dunia sehari-hari (Adnyana, 2017b: 33).

Tema sentral yang dimaksud semacam pembingkaian besar untuk menamai keseluruhan cerita yang dipahat. Walau memang setiap adegan memiliki cakupan makna tersendiri, karena setiap gerak figur, peralatan hidup yang melingkupi, berikut interaksinya dengan unsur visual yang lain menunjuk pesan khusus. Semisal adegan 'berburu macan', bercerita tentang romantisisme kepahlawanan sehari-hari orang Bali dalam perjuangan hidup dan juga perjuangan politik masa era Bali Kuno (Adnyana, 2018: 147). Perjuangan politik yang dimaksud berhubungan dengan cerita perlawanan rakyat Bali dalam menghadapi ekspansi kerajaan Majapahit di era akhir Bali Kuno.

Konsep multinarasi yang dimaksud telah dieksplorasi ke dalam seni lukis kontemporer dengan tujuh pendekatan artistik, yakni pada cara gambar, mewarnai, komposisi, memilah objek, teknik gunting, mengolah ruang, dan dekonstruksi tematik pada 2018. Sementara pada penelitian terapan tahun ketiga ini (2019), temuan konsep multinarasi dikembangkan ke arah penemuan konsep metafora. Konsep ini berangkat dari interpretasi atas motif, simbol, dan alegori, yang dimaksud dengan interpretasi ikonologis (D’Alleva, 2005: 24).

Temuan konsep metafora nantinya akan dieksplorasi ke dalam seni lukis kontemporer dengan mengembangkan temuan artistik menjadi temuan estetika. Temuan estetika yakni menunjuk pada upaya perumusan konsep keindahan, tidak saja bersifat formal (kebentukan), melainkan terkait konsep eksplorasi atas motif, simbol, dan narasi/ alegori relief Yeh Pulu ke dalam media seni lukis kontemporer. Konsep estetika menjadi dasar pembingkaian atau eksplorasi dari objek visual ke praktik penciptaan karya.

\section{METODE}

Penelitian terapan ini dilakukan melalui dua tahap, yakni penelitian berbasis riset lapangan untuk mengamati dan mengkaji relief Yeh Pulu untuk menemukan konsep metafora baru, kemudian tahap penciptaan karya seni lukis kontemporer. Penelitian terapan tahun ketiga (2019) ini, dilakukan berdasar analisis ikonologi Panofsky. Teori ikonologi mencakup tiga tingkatan analisis, yakni: pra-ikonografi, analisis ikonografi, dan interpretasi ikonologi (Panofsky, 1971: 14). Tahun ketiga penekanannya pada interpretasi ikonologi untuk menemukan konsep metafora baru.

Metode penciptaan dilakukan dengan prinsip 'art practice as a research' (Sullivan, 2005: 124) yang menekankan penciptaan seni sebagai proses penelitian. Pada konteks penciptaan seni lukis kontemporer ini, penciptaan dilakukan dengan tahapan eksperimentatif, yakni: eksperimen medium, bahasa visual, dan penyusunan konteks yang relevan (2005: 124). Eksperimen medium dan perumusan bahasa visual pada tiga tahun terakhir telah membentuk tujuh (7) pendekatan artistik, yaitu: teknik gambar garis, pewarnaan Bali dan kontemporer, menggunting objek, memilah objek, pengomposisian, lapisan warna/ruang imajinatif pada latar belakang, dan dekonstruksi tema.

Temuan konsep metafora baru nantinya akan mengembangkan pendekatan dekonstruksi tema yang dimaksud ke arah lebih kreatif, progresif, dan maju. Sehingga temuan yang terumuskan kemudian, meningkat dari pendekatan artistik, menjadi pendekatan estetika.

\section{METAFORA BARU}

Interpretasi ikonografi dalam pandangan Panofsky, dilakukan melalui langkah tafsir investigatif atas makna dari motif, simbol, dan alegori dalam konteks budaya pemiliknya (Panofsky, dalam D’Alleva, 2005: 23). Pandangan Panofsky ini sangat terpengaruh dari teori 'Significant Form' Ernst Cassirer bahwa imaji (bentuk/wujud) merupakan gambaran fundamental atau ide (nilai simbolik) dari budaya yang melatari, sehingga teori ini berpandangan bahwa karya seni itu 'dokumen' dari senimannya, agama, filsafat, atau peradaban (Cassirer, dalam D'Alleva, 2005: 23).

Mengikuti uraian D'Alleva, jelas antara motif, simbol, dan alegori/narasi merupakan untaian yang tidak terpisahkan. Motif sebagai entitas kebentukan yang unik, kemudian menunjuk pada simbol sebagai bentuk-bentuk personifikasi (seperti rupa binatang tertentu, atau figur manusia). Narasi atau alegori membingkai simbol sebagai representasi sebuah ide atau entitas. Kesemuanya hadir dalam konteks budaya pendukungnya. 


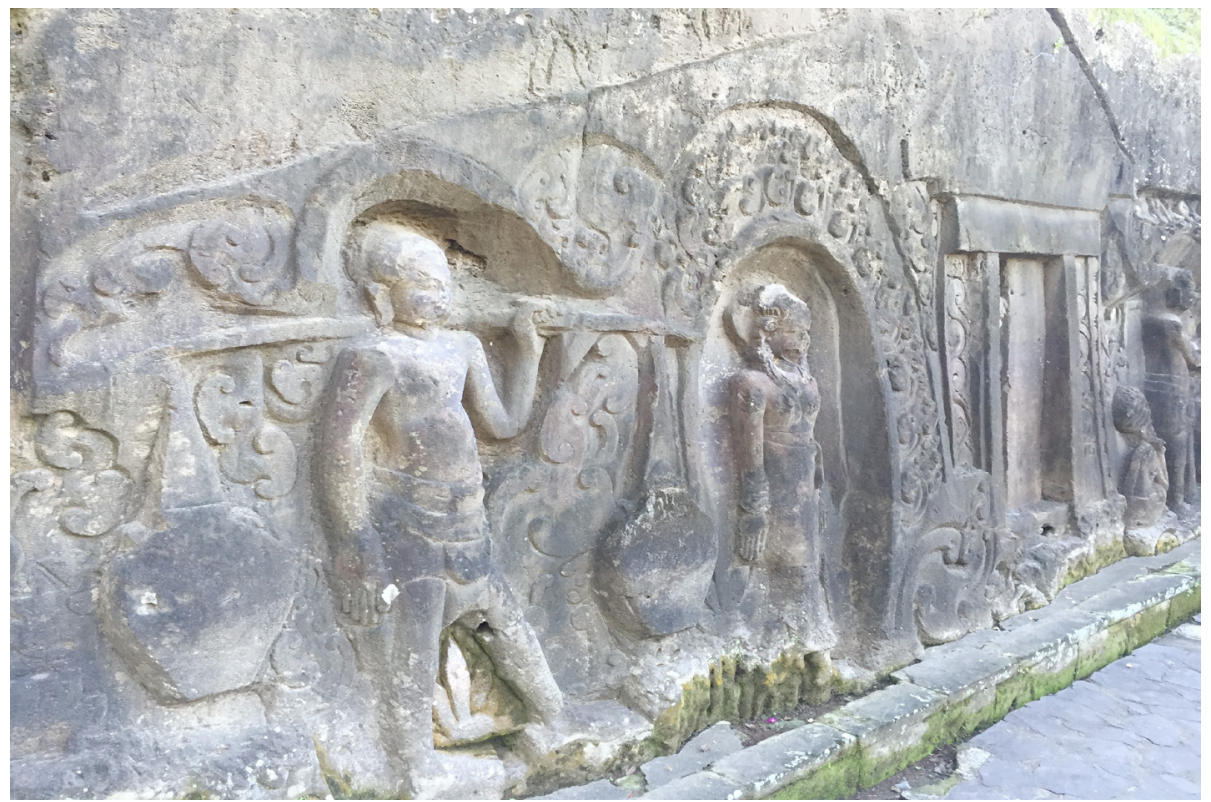

Gambar 1. Petikan relief Yeh Pulu, nampak adegan lelaki penjual tuak, dan penggambaran seorang putri. (Foto oleh I Wayan Adnyana)

Khusus tentang alegori, interpretasi atas narasi yang tertatah pada relief Yeh Pulu telah dilakukan pada 2018, dengan temuan konsep kemultinarasian (Adnyana, 2018b: 47). Sehingga pada penelitian ini penekannya pada interpretasi atas motif dan simbol, yang kemudian rumusannya menjadi temuan konsep metafora baru.

Investigasi konsep multinarasi didasarkan pada penelusuran bahwa setiap sistem narasi, atau cerita dalam suatu plot pada relief Yeh Pulu tidak dalam hubungan sebab-akibat. Seperti di ruang eksterior, yang memahatkan adegan 'berburu macan' sementara pada samping kanan atas adegan itu terdapat adegan laki-perempuan sedang 'pesta minum' barangkali itu minuman jenis teh, karena poci yang di tengah terlihat berasap. Hubungan antar adegan lebih pada kondisi laten, berturutan secara tidak langsung, yakni untuk merepresentasikan keberagaman aktivitas 'kepahlawanan' sehari-hari.

Konsep multinarasi, untuk kemudian menunjuk pada rumusan konsep metafora baru, maka dilakukan penyelidikan atas motif dan simbol-simbol. Karena berdasarkan motif dan simbol dapat merumuskan metafora, yakni bentuk-bentuk personifikasi dari relief Yeh Pulu. Kepentingannya bahwa metafora, yang kemudian dilukiskan pada tahap penciptaan seni lukis kontemporer identik dengan ikonografi yang terdapat pada pahatan relief Yeh Pulu.

Motif pada pemahaman ini lebih dimaknai sebagai entitas bentuk yang merepresentasikan 'dokumen' seniman pemahatnya, atau pun gambaran relegi dan filsafat kebudayaan yang melingkupi. Sehingga motif, tidak semata pelukisan tentang ragam hias. Motif lebih pada entitas perupaan yang unik, khas, dan juga memiliki relevansi dengan konteks budaya pengusung artefak yang dimak- sud. Seperti, pola stilisasi figur-figur manusia pada relief Yeh Pulu, cenderung naturalistik, karena mendekati proporsi tubuh manusia normal, tidak banyak ornamen yang melekat pada badan, dan juga gerak tubuh identik dengan perilaku keseharian. Begitu juga penggambaran binatang, baik piaraan maupun liar juga dipahatkan mendekati naturalistik. Jenis motif pada relief Yeh Pulu dapat dibagi atas: motif binatang, motif figur manusia, motif struktur bangunan, motif tumbuh-tumbuhan, dan ragam hias. Kesemua motif ditatah mendekati naturalistik, atau penggambaran alamiah seperti alam nyata.

Motif-motif tersebut, kemudian menunjuk pada simbol-simbol tertentu, yang dapat dibingkai dari setiap adegan. Karena setiap adegan merupakan bentuk personifikasi dari sebuah ide tentang kepahlawanan sehari-hari orang Bali pada jamannya, yakni seputaran awal abad ke-14. Setiap adegan yang terpahat pada relief Yeh Pulu memang tidak selalu terhubung dalam relasi sebab-akibat, tetapi masing-masing adegan tersusun atas motif, simbol, dan narasi yang sebangun.

Metafora dalam konteks pahatan relief Yeh Pulu adalah satuan setiap adegan yang tersusun atas hubungan dan kemiripan motif, simbol, dan narasi. Ini sebangun dengan bingkai konsep metafora, yakni kiasan yang merupakan kombinasi dari rakitan (unsur) yang serupa/mirip (combination appealing to the relationship of 'resemblance') (Jakobson dalam Surette, 1987: 570).

Metafora baru yang terbentuk sebagai luaran interpretasi ikonografi, adalah pembingkaian atas kesatuan motif, simbol, dan narasi pada masing-masing adegan. Seperti penjual tuak, dengan motif figur lelaki jangkung beserta simbol dua bejana yang tergantung pada tangkai kayu, 


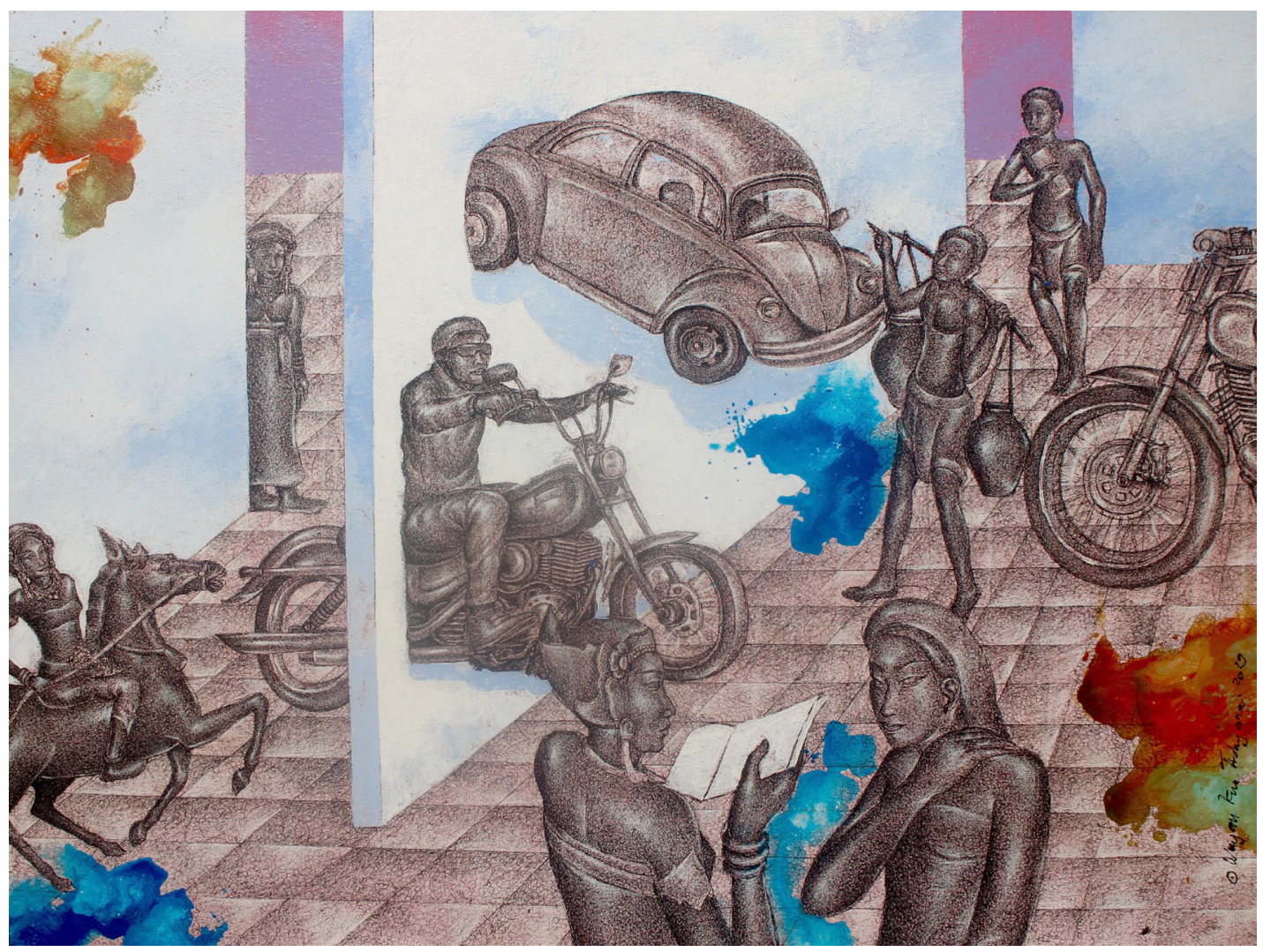

Gambar 2. Lukisan karya I Wayan Adnyana, judul The Old Modernism Artifact, 100X120 Cm, tinta dan akrilik di kanvas, 2019

menjadi satu metafora. Begitu juga metafora tentang 'pemburuan macan', 'pesta minum teh', 'pangeran mengendarai kuda', dan lain-lain.

Temuan metafora ini, kemudian menjadi basis penciptaan seni lukis kontemporer, untuk menghasilkan representasi metafora baru. Representasi yang dilakukan melalui eksperimen medium, perumusan bahasa visual, dan penyusunan konteks yang relevan. Tahapan penciptaan ini yang mengolah konsep metafora pahatan relief Yeh Pulu, menjadi metafora baru dalam bingkai seni lukis kontemporer. Setiap tahapan memproyeksikan temuan konsep estetika.

\section{TIGA PENDEKATAN ESTETIKA}

Metafora seperti 'berburu macan', 'pangeran mengendarai kuda', 'pemburu membawa hasil buruan babi hutan', dan lain-lain dieksplorasi ke dalam seni lukis kontemporer. Melalui tiga pendekatan praktik penciptaan, berdasar prinsip 'art practice as a research' (Sullivan, 2005: 124), yakni eksperimen medium, perumusan bahasa visual, dan penyusunan konteks yang relevan.

Tahap eksperimen medium, tahun ketiga (2019) penelitian terapan ini menguatkan tujuh pendekatan artistik yang telah ditemukan pada 2018 lalu, yaitu: teknik arsir garis (drawing), pewarnaan (coloring), teknik pemotongan objek gambar (cutting), pengomposisian/pemecahan objek (smashing), lapisan warna yang meruang (layering), pemilihan objek gambar secara fokus (highlighting), dan dekonstruksi (deconstructing). Ketujuh pendekatan artistik ini tidak seluruhnya dipakai dalam setiap karya. Melainkan dipilih pendekatan, atau teknik yang relevan dengan kebutuhan untuk mencapai visual karya yang unik, berkarakter, dan kontemporer.

Pendekatan teknik arsir dengan medium tinta menjadi pilihan mayoritas, karena nyaris setiap subjek utama karya menggunakan teknik ini. Hal ini dimaksudkan untuk membangun kesan khas, dan juga berkarakter. Terlebih teknik arsir berupa tumpukan garis lengkung itu diformulasi dengan pendekatan pewarnaan minimalis, dalam pengertian, warna hadir sebagai aksen kontras semata, bukan untuk memoles keseluruhan subjek gambar. Karakter visual kontemporer, salah satunya dimunculkan dengan memaknai kontras, atau bahkan luberan warna (terkesan seperti warna tumpah) sebagai penanda baru. Seperti pada lukisan 'The Old Modernism Artifact', 2019, kehadiran tumpahan warna biru dan juga oranye kehijauan, menjadi penanda visual, antara membangun imaji seperti visual foto kuno atau efek kejut visual (permukaan lukisan yang terkena tumpahan cat warna).

Selain tentang pewarnaan, dalam eksplorasi medium juga mengakomodasi pendekatan pengomposisian yang khas, termasuk di dalamnya upaya pemilihan subjek gambar 


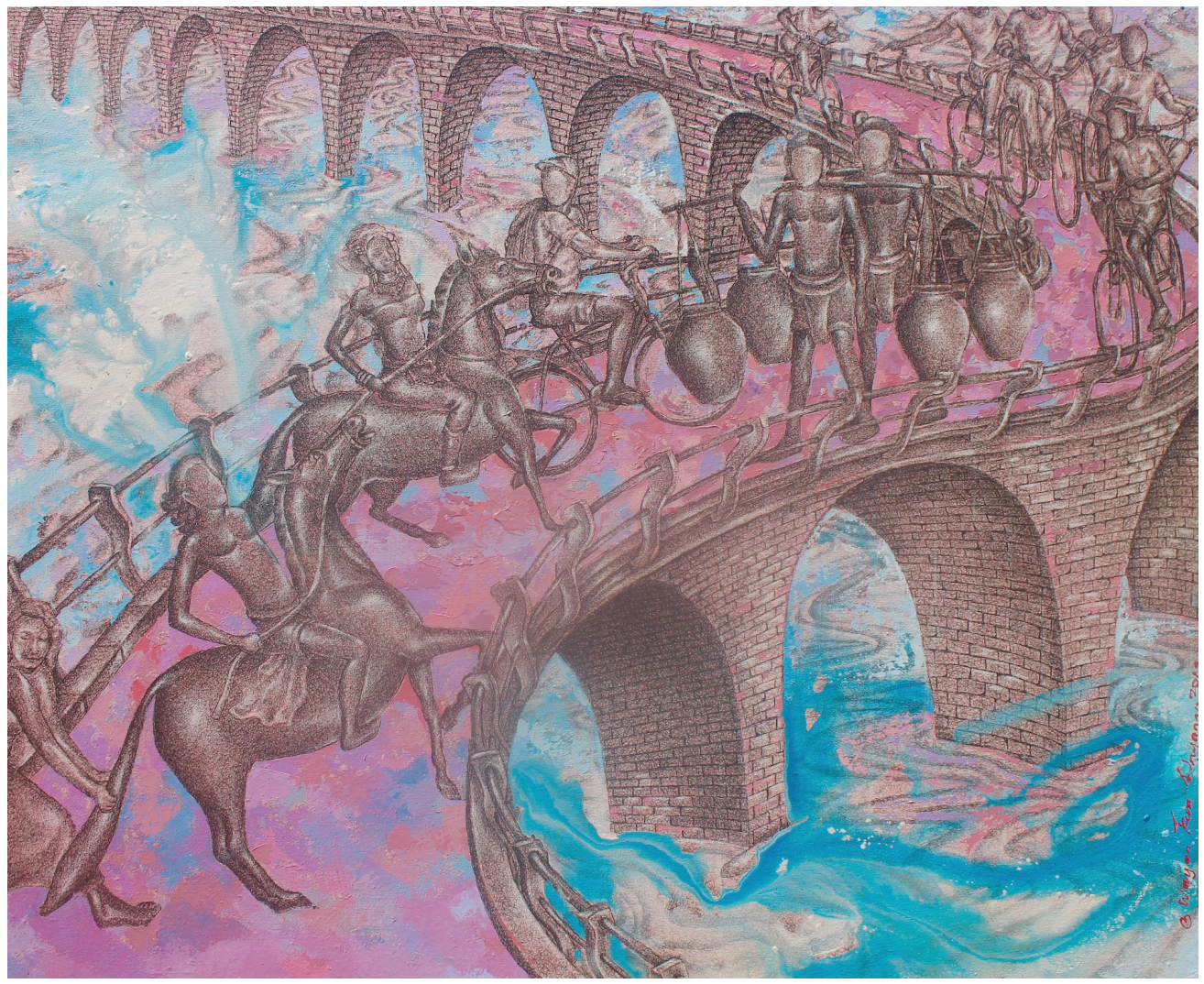

Gambar 3, karya I Wayan Adnyana, judul 'The Pink Bridge', tinta dan akrilik di kanvas, 100x120 Cm, 2019

berdasar temuan konsep metafora baru. Adegan-adegan pahatan relief Yeh Pulu, seperti 'berburu macan', penampilan 'seorang putri' dengan busana khas berdasar ikonografi Yeh Pulu, dan adegan lain hadir sebagai metafora (subjek utama pada karya). Adegan-adegan tersebut dipilih, kadang dipertemukan dengan adegan lain, kadang juga hanya hadir tunggal.

Pada tahap kedua, perumusan bahasa visual, dikembangkan gubahan bahasa visual dengan tetap mempertahankan ciri figurasi relief Yeh Pulu. Pemilahan dan pemilihan subjek gambar (berbasis adegan) dilakukan dengan pertimbangan tema yang relevan. Hal ini menunjuk pada tahap penciptaan ketiga, yakni merangkai konteks yang relevan. Seperti pada karya 'The Old Modernism Artifact', yang membangun sambungan antara figur-figur relief Yeh Pulu, seperti 'seorang putri', 'pedagang tuak', atau adegan dekonstruktif 'seorang putri yang menunggang kuda', dan lain-lain justru dalam peran sebagai pengunjung pameran (museum). Sementara artefak koleksi museum adalah deretan produk teknologi, seperti mobil dan motor besar.

Bangunan konteks yang membalikkan, yang kuno sebagai realitas hari ini, dengan menempatkan figur-figur relief Yeh Pulu sebagai penonton, sementara karya teknologi manusia modern justru sebagai artefak museum. Hal ini dilakukan berdasar pemahaman, bahwa praktik penciptaan seni lukis kontemporer berhubungan dengan budaya visual (visual culture), yang kemudian menunjuk entitas budaya seni (art culture), seperti ide pembingkaian ulang pada lukisan, atau perombakan pada patung (Marriner, 2017: 165-166). Istilah pembingkaian ulang dan perombakan (ulang) dalam konteks tiga pendekatan estetika seni lukis kontemporer ini, muncul dari pandangan Marriner dalam menghubungkan keberadaan seni lukis kontemporer dengan budaya visual (budaya massa dan budaya populer).

Artinya, penciptaan seni lukis kontemporer bukan bermotivasi untuk melukis ulang sebuah objek gambar. Melainkan hadirnya konsep budaya visual di dalam lingkup praktik penciptaan, yakni dengan menggabung-sambungkan visual (subjek gambar) yang relevan atau tidak sebagai bangunan konteks tematik karya.

Formulasi ketiga tahapan, eksplorasi medium, penyusunan bahasa visual, dan perumusan konteks yang relevan, dalam penelitian terapan 2019 ini menemukan tiga konsep pendekatan estetika, yakni: pembingkaian ulang (reframing), perombakan ulang (recasting), dan mobilitas ke konteks ruang global (mobilizing).

Ketiga pendekatan estetika ini, menunjuk pada upaya membangun memori generasi kini tentang artefak sejarah masa lalu. Penguatan memori penting dilakukan untuk menggugah pemahaman nilai-nila kepahlwanan yang melekat pada pahatan relief Yeh Pulu. Ketiga pendekatan 
estetika yang ditemukan ini memproyeksikan narasi relief Yeh Pulu tetap hidup pada ruang, situasi, dan kondisi sosial urban global sekalipun.

Temuan tiga pendekatan estetika ini, juga berkontribusi pada pengayaan pola stilistik, nuansa artistik, dan juga pola representasi gambar. Kekontemporeran visual teramu dari masuk berkelindan berbagai unsur visual, baik itu karakter stilistik kuno relief Yeh Pulu, dengan stilistik objek teknologi modern, seperti kehadiran berbagai alat elektronik dan otomotif modern.

Ketiga pendekatan estetika tersebut lebih sering dipergunakan utuh pada setiap karya. Hanya beberapa karya yang menggunakan satu atau dua pendekatan. Seperti karya 'The Old Modernism Artifact' dan 'The Pink Bridge', keduanya menggunakan ketiga pendekatan estetika yang dimaksud. Pembingkaian ulang, pada kedua lukisan tersebut menunjuk pada penempatan figure-figur (metafora) relief Yeh Pulu pada format tidak lagi sebagai relief yang terpahat pada dinding batu padas. Melainkan hadir sebagai figur selayak manusia yang memiliki kemampuan untuk berpindah tempat. Seperti jalan-jalan di tepi sungai, melintasi jembatan, melihat museum, dan lain-lain.

Format visual seperti ini dinamai sebagai pembingkaian ulang (reframing). Kemudian, di dalamnya ada perombakan atas adegan, seperti pada relief Yeh Pulu yang terpahat adalah seorang pangeran mengendarai kuda, pada karya 'The Old Modernism Artifact' justru yang mengendarai kuda adalah seorang putri. Perombakan ini, pada pendekatan artistik (2018) dinamai sebagai pendekatan 'dekonstruksi'. Berikut pemindahan tempat ke ruang global (mobilizing), dimaksudkan sebagai upaya menghadirkan figur atau adegan pahatan relief Yeh Pulu ke ruang-ruang publik modern (global). Seperti figur relief Yeh Pulu hadir jalan-jalan di jembatan, museum, maupun ruang publik lain, dan berbaur dengan figur atau sosok manusia modern. Hal yang bersambung dari penelitian terapan sebelumnya (2018), yakni tentang konsep kemultinarasian. Konsep narasi sebagai metode narasi, tujuannya adalah sebagai akses dan representasi titik pandang yang jamak (multiple viewpoints) (Leavy, 2015: 46). Representasi dengan multi sudut pandang ini terlihat melalui upaya pembingkaian ulang, perombakan, dan mobilitas subjek adegan pahatan relief Yeh Pulu ke dalam format keruangan, situasi, dan objek pendukung lain yang berubah. Adegan pahatan relief Yeh Pulu hadir dalam fenomena jaman masa kini, sehingga narasi yang muncul berkembang dan berubah. Namun narasi di dalam adegan itu sendiri kadang tetap utuh bertahan. Seperti, adegan 'pangeran mengendarai kuda' atau pun 'penjual tuak' tetap hadir seperti adanya, namun kemudian dipindahkan penempatannya pada ruang-ruang sosial modern dan kosmopolitan.

Karya 'The Pink Bridge' merepresentasikan kehadiran adegan 'pangeran mengendarai kuda' pada jembatan mod- ern berwarna merah jambu. Ini tentu representasi yang tidak pernah diduga. Karena penggambaran adegan relief Yeh Pulu tidak pernah dipecah, atau pun dipilah peradegan. Terlebih adegan itu dipindah ke ruang sosial baru (modern dan kosmopolitan), belum pernah ditemui. Pola penyusunan narasi dengan berbagai sudut pandang ini, seperti dituliskan Leavy, disebit sebagai metode narasi.

Artinya, tiga pendekatan estetika: pembingkaian ulang (reframing), perombakan (recasting), dan pemindahan (mobilizing) itu menyusun narasi dengan metode narasi. Ketiga pendekatan ini, yakni menyusun narasi melalui pengembangan konsep dekonstruksi; mencairkan yang binner, oposisif, dan berlawanan ke ruang yang saling bertautan, bersambung, dan kolaboratif. Situasi naratif yang saling bertaut inilah dipahami sebagai situasi metaforik. Sementara subjek gambar yang hadir sebagai metafora baru. Adegan relief Yeh Pulu yang bersambung dengan beragam adegan dan format keruangan modern, merupakan realitas metaforik.

Konsep 'kepahlawanan sehari-hari orang-orang biasa' yang memayungi keseluruhan temuan interpretasi ikonografi relief Yeh Pulu tetap tidak hilang dalam representasi realitas metaforik ini. Kehadiran petikan adegan relief Yeh Pulu pada ruang, situasi, dan konteks sosial modern dan kosmopolitan, justru semakin menguatkan konteks kepahlawanan sehari-hari itu. Seperti kehadiran 'penjual tuak' di berbagai situasi, termasuk memasuki ruang museum modern. Situasi urban global, memberi ruang kehadiran multibudaya dalam konteks masa kini. Sejarah kuno tidak menjadi masa lalu, melainkan hadir berkelindan dengan masa kini yang modern kosmopolitan.

Ketiga pendekatan estetika tersebut, menjadi jawaban atas kehendak merepresentasikan kepahlawanan sehari-hari masa abad ke-14, ke dalam situasi hari ini. Hal tersebut dapat menguatkan memori generasi kini, atas sejarah dan juga konteks narasi sosial yang melingkupi.

\section{SIMPULAN}

Representasi narasi 'kepahlawanan sehari-hari' relief Yeh Pulu ke dalam ruang, situasi, dan kondisi sosial modern (urban global) dilakukan melalui tiga pendekatan estetika: pembingkaian ulang (reframing), perombakan (recasting), dan pemindahan (mobilizing). Pembingkaian ulang berarti perubahan format narasi, dari struktur narasi/adegan relief Yeh Pulu ke struktur narasi baru. Seperti, adegan 'pangeran mengendarai kuda' diubah menjadi 'pangeran mengendarai motor besar', dan lain-lain. Sementara perombakan (recasting) berarti pengalihan, penukaran, atau penggantian peran di dalam struktur narasi relief Yeh Pulu itu sendiri. Semisal, adegan 'pangeran mengendarai kuda' menjadi adegan 'putri mengendarai kuda'. Konsep pemindahan (mobilizing), merupakan penempatan adegan relief Yeh Pulu ke dalam format ruang, situasi, dan kondisi 
sosial yang berbeda (urban global). Sebut misalnya, karya "The Pink Bridge" sosok pangeran dan putri pengendara kuda dihadirkan melintasi jembatan berwarna merah jambu.

Pendekatan estetika tersebut ditemukan melalui tiga tahap penciptaan seni, yakni eksplorasi medium, perumusan bahasa visual, dan penyusunan konteks yang relevan. Pada eksplorasi medium ditentukan pendekatan gambar garis sebagai pilihan utama, untuk memperkat visual metaforik Yeh Pulu dalam ruang komposisi baru. Selain gambar garis juga pendekatan pewarnaan yang khas, yakni dengan memoles bidang-bidang untuk memunculkan kesan ruang, dan juga teknik luberan warna alamiah. Khusus untuk luberan cat (warna) alamiah, dapat dilihat pada pewarnaan air pada karya "The Pink Bridge", atau juga tune warna kontras pada karya 'The Old Modernism Artifact'.

Perumusan bahasa visual ditentukan dengan menyusun komposisi secara bebas. Ruang pemandangan, ruang kamar, dan ruang tanpa batas menjadi basis penempatan objek gambar relief Yeh Pulu. Sehingga semua ruang teridentifikasi, dan ditunjang oleh kehadiran objek budaya visual (populer) sebagai penunjang bahasa visual. Konsep kekontemporeran juga dirumuskan melalui tahap penyusunan bahasa visual tersebut.

Perumusan konteks yang relevan, lebih pada upaya terjemahan dari konsep dekonstruksi, dan juga konsep metode narasi. Kemultinarasian dipadu dengan kemultian sudut pandang, sehingga yang terepresentasi narasi relief Yeh Pulu dalam berbagai format ruang, tipe narasi, dan juga suasana budaya yang beragam.

Ketiga pendekatan estetika ini merupakan metode narasi, yakni memandang sistem narasi yang bertumpu pada multi sudut pandang. Multi sudut pandang, dapat ditemukan dari pertemuan narasi kuno (adegan relief Yeh Pulu) dengan narasi sosial global hari ini. Sudut pandang yang lain, yakni perombakan struktur narasi di dalam narasi kuno itu sendiri, melalui metode perombakan (recasting). Begitu juga adanya pemindahan, dari 'pesta minum teh' pada pahatan Yeh Pulu, kemudian diformat pada narasi pesta minum teh di dapur rumah modern.

Artikel ini merupakan bagian dari hasil Skema Penelitian Terapan tahun ketiga (2019), berjudul Ikonografi Kepahlawanan Relief Yeh Pulu. Basis Penciptaan Seni Lukis Kontemporer, yang dibiayai Diretorat Riset dan Pengabdian Masyarakat (DRPM), Kementerian Riset, Teknologi, dan Pendidikan Tinggi, tahun anggaran 2019. Untuk itu ucapan terimakasih disematkan kepada Diretorat Riset dan Pengabdian Masyarakat, Direktorat Jenderal Penguatan Riset dan Pengembangan, Kementerian Riset, Teknologi, dan Pendidikan Tinggi di Jakarta, dan jajaran Lembaga Penelitian, Pengabdian Masyarakat, dan Pengembangan Pendidikan (LP2MPP) ISI Denpasar.

\section{DAFTAR RUJUKAN}

Adnyana, I Wayan. 2017b, Ikonografi Kepahlwananan Relief Yeh Pulu (Penelitian, Penciptaan, dan Penyajian Seni Lukis Kontemporer): Buku Ajar, Penerbit Arti, Denpasar.

2018, "Tiger-Hunting Scence on Yeh Pulu Relief in Bali. Romanticism of People's Heroism in the Study of Iconology", Cultura. International Journal of Philosophy of Culture and Axiology, Vol. 15/1.

2018b, Multinarasi Relief Yeh Pulu. Tujuh Pendekatan Artistik Seni Lukis Kontemporer: Buku Ajar, Penerbit Arti, Denpasar.

Adnyana, I Wayan., Anak Agung Gde Rai Remawa, dan Luh Desi In Diana Sari, 2018, "Multinarasi Relief Yeh Pulu, Basis Penciptaan Seni Lukis Kontemporer", Mudra Jurnal Seni Budaya, Volume 33, Nomor 2, Mei, Pusat Penerbitan, ISI Denpasar.

D’Alleva, Anne. 2005, Methods Theories of Art History, Laurence King Publishing, London.

Leavy, Patricia. 2015, Method Meets Art. Arts-Based Research Practice (Second Edition), Guilford Press, New York.

Marriner, Robin. 2017, "Visual Culture and Contemporary Art: Reframing the Picture, Recasting the Object?", dalam The Handbook of Visual Cuture, editor Ian Heywood dan Barry Sandywell, Bloomsbury, London dan New York.

Panofsky, Erwin. 1971, Studies in Iconology, Icon Edition, Colorado.

Sullivan, Graeme. 2005, Art Practice as Research, Sage Publication, London.

Surette, Leon. 1987, "Metaphor and Metonymy: Jakobson Reconsidered", University of Toronto Quarterly, Volume 56, Number 4, Summer. 